\title{
A THOROUGH STUDY ON PRODUCT RECOMMENDATION
}

\author{
Aniket Tale, Suraj Patil, Snehal Lodade, Pratik Sonawane \\ Computer dept., GHRCEM, Pune \\ Prof. Suvrana Satkar \\ Computer dept., GHRCEM, Pune
}

\begin{abstract}
The improvements in the internet infrastructure and the increased affordability has led to an increase in the number of users on this platform. This has put a large impact on the services being offered on this platform especially on the e-commerce websites. These websites cater to the individual and the increased number of users has led to an increase in customer data. This data is highly valuable as it can allow for the effective prediction of customer behavior. Therefore, these predictions can allow for effective and accurate product recommendations based on the interests and the behavior of the customer. To achieve this approach, this research article analyzes a collection of related works based on the paradigm of product recommendation. After a thorough analysis, an improved product recommendation system is devised through the effective implementation of Natural Language Processing and machine learning algorithms. The proposed methodology performs preprocessing, Bag of Words, and TF-IDF along with Fuzzy Artificial Neural Networks and Collaborative Filtering to achieve an effective Product Recommendation system. This approach will be expanded further in the upcoming researches.
\end{abstract}

Keywords: Natural Language Processing, Fuzzy Artificial Neural Networks and Collaborative Filtering

\section{INTRODUCTION}

In this information age, there has been increased number of devices such as smartphones and other electronic devices. This is due to the increase in the efficiency that reduces the price of the electronic devices. These devices have become increasingly affordable as they are easier to produce. This allows a large number of individuals to own such devices and use them on a large scale. The rise in the affordability of these devices which has led to a large number of individuals getting access to the internet platform. The internet service providers have also found an incentive to reduce the price of the subscriptions as a large number of people are being added to the user base. This increase in the number of the individuals as the users of the platform creates an effective feasibility to keep competitive pricing which makes it increasingly affordable for the common people to get access to the internet platform.

The increase in the individuals has also provided and incentive to the services offered by the internet. The increase in the user base allows the effective implementation of these services to be able to cater to the large number of individuals. One of the most effective and useful approaches that are used by a large number of individuals online are the social networking and the e-commerce websites. The E-commerce websites are highly useful as it allows the individual to order various products online and get them delivered at their doorsteps.

The increased convenience offered by such outlets have been embraced by the individuals in large numbers. This has resulted in a large number of various E-commerce websites that have been cropping up on the internet with the intent to grab the market and make their presence felt. These ecommerce websites are vying for the user base and the increased revenue offered by these individuals. For this purpose the websites are providing various offers and other approaches to grab individuals. These websites ignore the current users of the websites that are using the website. This leads to a large number of individuals leaving the platform for more lucrative offers.

Therefore, the users can be retained using various techniques, especially by making them stay on the platform through increasing their convenience of the users effectively. This can be achieved through the use of an effective recommendation system that can provide the users with the relevant recommendations. Therefore, for this purpose a collection of researches have been surveyed in this research article. These researches have been useful in achieving our approach for the recommendation system which utilizes Natural Language Processing approach along with Fuzzy Artificial Neural Network and Collaborative Filtering.

This literature survey paper dedicates section 2 for analysis of past work as a literature survey, and finally, section 3 concludes the paper with traces of future enhancement. 


\section{International Journal of Engineering Applied Sciences and Technology, 2021 \\ Vol. 5, Issue 10, ISSN No. 2455-2143, Pages 200-202 \\ Published Online February 2021 in IJEAST (http://www.ijeast.com)}

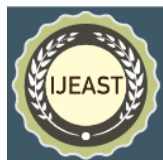

\section{RELATED WORKS}

H. Afsarmanesh defines recommendation system has it suggest appropriate choice, e.g. Fitting sub-product, considering the set of user's preferences and requirements. The recommender system can be used the increase crossselling and user satisfaction. In the proposed paper the recommender system helps designers of sub-products with reusing the existing specifications thus for recommending business services. [1]If there is any complex case they use a different level of reusability such as product specification, from features and feature-kinds to sub-products and classes.

Y. Chen presents a recommendation system for product empirical knowledge consultation by using matchmaking of the required consultative experts quickly and correctly thus for product knowledge.[2] The proposed paper works on designing an expert recommendation for process empirical knowledge consultation, developing an expert recommendation method, and developing an expert recommendation method. Product empirical knowledge includes two phase's personal ontology construction and integration of personal ontology and global ontology.

Y. Wang in the industry especially for e-Commerce company product recommendation system has been widely used. To get competitive benefits in this competitive and diversified global marketplace custom product design implement various strategies. Dell Computer is known for the most successful product customization cases they have an advantage and maintained high profitability in the PC industry for a very long time. But still, custom product design is treated as a trial and error procedure. [3] Thus the proposed paper author came with a solution called information overload they directly communicate with customers regarding the product development team via minimum involvement of middlemen.

J. Hsiao states due to the explosive growth of the online shopping market process of guiding the user to the huge amount of online products are a very challenging part. [4] To make recommendations recommender systems use information from users' profiles, similar neighbors, and textual descriptions this method can create an irrelevant suggestion to users due to the ignorance of users' intentions. In the proposed system the researcher implements an interactive product recommendation method that not only considers visual similarity but also product diversity. The proposed algorithm is evaluated under a real-world user log and it as an effective result.

C. Cavalcante estimates the Internet of Things (IoT) technologies play an important role to come up with new functionalities to society. [5] IoT contains a new technological method that can be defined as a network that connects devices, "things." IoT is known for virtual identity and communication through the Internet with peoples, society, and the environment. Thus due to this kind of functionalities IOT can use the Product Development Process (PDP) when developing and spreading the array of intelligent products. Thus in the proposed paper by incorporating IoT technologies the process of developing intelligent products for recommendations is proposed.

S. Weng presents a system to analyze customers' purchasing behaviors based on product features from transaction records and product feature databases just to know their shopping habits and to recommend customers products that have a potential attraction with a customer. The main aim of the proposed paper is to recommend to customers brand new products as they should fit in the customer interest profiles. [6] Due to the internet, the growing trend of customer personalization has been increased. The purpose of the paper is very clear to provide personalized product recommendation and to increase the accuracy of recommendation

M. Lian explains there are variety and quantity of Internet financial products due to internet growth it is very challenging to implement personalized recommendation [7]. The timing factor is very important in financial product recommendations. Thus in the traditional method, the timing factor was ignored and they used to concentrate on the static attributes of users and financial products. But has now there is a huge development in the field of artificial intelligence, deep learning technology the proposed paper has developed the framework by using R-Transformer is a Recommendation system based on a transformer.

C. Hsu explains it is very hard to understand consumers because most cosmeceutical products ingredients are shown in English. These English ingredients are usually long and complex [8]. The main purpose of the proposed research is to provide an ingredient retrieval and recommendation system for the product. Shopping for a cosmeceutical product is very hard these days because they have many choices. Just because of the advancement of Internet technology people can gain information about any products. The proposed system is implemented on the Android mobile phone it can make it easy for consumers to retrieve and recommend easy.

N. Iswari explains due to the internet purchase of goods and sale have started to move from being offline to online and it is known as e-commerce. The huge development has been made in the field of internet and intelligent computing technology because of e-commerce is increasingly being used. Thus the proposed paper develops the framework called product recommendation system according to user needs. In the proposed paper they have used Slope One algorithm based on the domain ontology of the product [9]. Domain ontology is used to set the relationships between products by using Collaborative Filtering.

N. Kumbhar narrates collaborative filtering and contentbased systems are the method used for the recommendation system. Items like actors, box office popularity, type, and so forth in case movies are included in content-based systems. Information like user browser history, transactions made, and the interest of users is included in Collaborative filtering (CF). 


\section{International Journal of Engineering Applied Sciences and Technology, 2021 \\ Vol. 5, Issue 10, ISSN No. 2455-2143, Pages 200-202 \\ Published Online February 2021 in IJEAST (http://www.ijeast.com)}

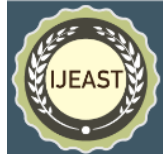

For mapping, user features from social media and product features from an e-commerce website by using feature-based matrix factorization method [10]. Thus the proposed paper recommendation system is accuracy improved.

N. Amran implements user Profile-based Product Recommendations on the Android platform (PBR app) to offer many benefits to the user. Whenever people visit malls or stores, users are usually served with a variety of products from different brands. Thus the people may face problems while selecting any product. To solve this issue the author develops a framework called User Profile Based Product Recommender which is an Android-based application [11]. The proposed application finds an easy way to find the product by scanning the product's barcode. They choose the Android platform due to its nature, which is very close and personal to the user.

\section{CONCLUSION AND FUTURE SCOPE}

The related researches on the topic of product recommendation system has been surveyed in this paper. These approaches have provided a valuable insight in the process of product recommendation. The product recommendation is one of the most effective and useful feature that can significantly reduce the effort of the user on the e-commerce website. The relevant and useful products needed by the user are conveniently searched and suggested to the user which can lead to increase in the user convenience. This increased convenience can be highly useful in retaining the users to this platform effectively. Therefore, an effective product recommendation system is the need of the hour to improve the conditions of the e-commerce platform. Most of the approaches with the product recommendation approach have been inconsistent and highly inaccurate. This leads to customer dissatisfaction. Therefore, an effective technique for product recommendation has been proposed which utilizes NLP along with Fuzzy ANN and Collaborative Filtering. This approach will be expanded further in the upcoming researches on this topic.

\section{REFERENCES}

[1] H. Afsarmanesh, M. Shafahi, and M. Sargolzaei (2015), "On service-enhanced product recommendation guiding users through complex product specification," 2015 International Conference on Computing and Communications Technologies (ICCCT), Chennai, 2015, pp. 43-48, DOI: 10.1109/ICCCT2.2015.7292717.

[2] Chen Y., Chen Y. and Wu M. (2010), "An expert recommendation system for product empirical knowledge consultation," 2010 3rd International Conference on Computer Science and Information Technology, Chengdu, 2010, pp. 2327, DOI: 10.1109/ICCSIT.2010.5563845.

[3] Wang Y. and Tseng M. M. (2009), "Recommendation for a custom product via probabilistic relevance model," 2009 IEEE International Conference on Industrial Engineering and
Engineering Management, Hong Kong, , pp. 1548-1552, DOI: 10.1109/IEEM.2009.5373093.

[4] Hsiao J. and Li L. (2014), "On visual similarity based interactive product recommendation for online shopping," IEEE International Conference on Image Processing (ICIP), Paris, 2014, pp. 3038-3041, DOI: 10.1109/ICIP.2014.7025614.

[5] Cavalcante C. G. S. and Fettermann, D. C. (2019)"Recommendations for Product Development of Intelligent Products," in IEEE Latin America Transactions, vol. 17, no. 10, pp. 1645-1652, October 2019, DOI: 10.1109/TLA.2019.8986442.

[6] Weng Sung-Shun and Liu Mei-Ju, (2004)"Personalized product recommendation in e-commerce," IEEE International Conference on e-Technology, e-Commerce and e-Service,. EEE '04. 2004, Taipei, Taiwan, 2004, pp. 413-420, DOI: 10.1109/EEE.2004.1287340.

[7] Lian M. and Li J. (2020), "Financial product recommendation system based on a transformer," IEEE 4th Information Technology, Networking, Electronic and Automation Control Conference (ITNEC), Chongqing, China, 2020, pp. 2547-2551, DOI: 10.1109/ITNEC48623.2020.9084812.

[8] Lian M. and Li J. (2020), "Financial product recommendation system based on a transformer," IEEE 4th Information Technology, Networking, Electronic and Automation Control Conference (ITNEC), Chongqing, China, 2020, pp. 2547-2551, DOI: 10.1109/ITNEC48623.2020.9084812.

[9] Iswari N. M. S., Wella W. and Rusli A. (2019), "Product Recommendation for e-Commerce System based on Ontology," 1st International Conference on Cybernetics and Intelligent System (ICORIS), Denpasar, Bali, Indonesia, 2019, pp. 105-109, DOI: 10.1109/ICORIS.2019.8874916.

[10] Kumbhar N and Belerao K (2017), "Microblogging Reviews Based Cross-Lingual Sentimental Classification for Cold-Start Product Recommendation," International Conference on Computing, Communication, Control and Automation (ICCUBEA), Pune, 2017, pp. 1-4, DOI: 10.1109/ICCUBEA.2017.8463697.

[11] Amran N. A. N., Zaini N, and Samad M (2014), "User profile based product recommendation on android platform," 5th International Conference on Intelligent and Advanced Systems (ICIAS), Kuala Lumpur, pp. 1-6, DOI: 10.1109/ICIAS.2014.6869557.

[12] Roy Ms. Susmita (2019), "Movie Recommendation System Using Semi Supervised Learning”, Global Conference for Advancement in Technology(gcat),2019. pp 1-8. 